\title{
Inspiring Work-Life Balance: Responsible Leadership among Female Pharmacists in the Egyptian Health Sector
}

\author{
Mohamed Mousa
}

\begin{abstract}
A B S T R A C T
Objective: The aim of the research was to investigate the effect of responsible leadership on female pharmacists' work-life balance/imbalance forms in public hospitals in Menoufia province, Egypt.

Research Design \& Methods: This is a quantitative study and a total of 350 female pharmacists were contacted. After four follow ups, a total of 230 responses were collected with a response rate of $65.71 \%$.

Findings: The findings highlighted only an aggregate of virtues and is not considered a strong statistical predictor for any of the three work-life balance/imbalance forms (time-based balance/imbalance, strain-based balance/imbalance and behaviourbased balance/imbalance) while the other three dimensions (stakeholder involvement, the model of leader's role and the principles of ethical values) of responsible leadership had a significantly high effect on work- life forms.
\end{abstract}

Implications \& Recommendations: Dependent and independent variables were collected from the same source, and this may have led to an inflation of statistical relationships. Public organisations like hospitals have to treat female pharmacists responsively as one of the main stakeholders who requires flexible work hours, active participation in decision making, and clear empowerment in the workplace.

Contribution \& Value Added: This article contributes by filling a gap in management and organisation literature, in which empirical studies on the relationship between responsible leadership and work-life balance/imbalance have so far been quite limited in the literature. For future studies, the author suggests testing the same propositions with physicians, nurses, and other categories of employees in Egyptian public hospitals.

\section{Article type: research paper}

Keywords: $\quad$ responsible leadership; work-life balance; Egypt; health care JEL codes: $\quad$ M14

Received: 10 October $2017 \quad$ Revised: 9 February $2018 \quad$ Accepted: 23 February 2018

\section{Suggested citation:}

Mousa, M. (2018). Inspiring a Work-life Balance: Responsible Leadership among Female Pharmacists in the Egyptian Health Sector. Entrepreneurial Business and Economics Review, 6(1), 71-90. https://doi.org/10.15678/EBER.2018.060104 


\section{INTRODUCTION}

Leadership style is an effective mechanism which prompts employees to innovate, business models to be checked and updated, work problems to be discovered and managed, and finally organisations to be driven in order to survive and prosper. However, leadership today is undergoing a transitional stage (Erkutlu \& Chafra, 2016). Scandals in organisations like Enron, Tyco and WorldCom along with the 2008 global economic crisis the world witnessed have raised questions about the relevance and adequacy of the known leadership styles (Inglehart, 2008). The role and accountability of business community leaders are also put to question. In this light, many business leaders and academic experts have realised that maximising businesses' profits cannot be the only target (Wade, 2006). And thus, any business attempt to maximise profit should be accompanied by a considerable concern for achieving the well-being of the environment that the firm operates in, the welfare of internal and external stakeholders the firm serves and the wisdom the firm employs when dealing with its staff (Hymavathi, Kasarabada, \& Avadhanam, 2015). This creates a space for what academicians choose to label 'responsible leadership' which urges organisations' leaders to maintain a noticeable commitment towards alleviating poverty, supporting peace, promoting freedom and safeguarding human rights in the communities their organisations serve (Bonoli, 2005; Carrasco, 2007; Avram \& Kunhe, 2008; Antunes \& Franco, 2016). Ciculla (2004), De Hoogh and Den Hartog (2008), Earley (1989), Eva and Sendjaya (2013) indicate that responsible leaders constantly disseminate the values of virtue, wisdom, empathy and sympathy for the betterment of their societies (Holt, 2006; Maak \& Pless, 2008; Morland, 2015). That is why, the studies of Fishbein and Ajzen (1975), Pless (2007) Maak and Pless (2009, 2011), Nonet, Kassel, and Meijs (2016) argue that social responsibility is the main challenge facing responsible leaders nowadays. Leadership research is no longer limited to the leader/followers relationship but instead it has expanded to cover the leader-stakeholder relationship. It is concerned with various ways in which stakeholders perceive such a relationship and that responsible leaders seek to support and maintain that relationship (Tran, Fallon, \& Vickers, 2016).

Over the last two decades, work-life balance has become a buzzword in various academic disciplines like human resources management, cultural diversity management, organisational communication, and organisational behaviour (Anderson, 1996; Anxo Franz, \& Kummerling, 2013). Due to the growing awareness of demographic changes, labour market participation, feminist active lobbying and paid employment, the concept has found its place in public policies of countries (Hennig, Gaterman, \& Hagglund, 2012). Therefore, many public and private employers have provided paid maternity and on-site childcare services as a part of their responsibilities towards employees (Emslie \& Hunt, 2009). However, with an increase in employees' average income and the socio-cultural shifts they experience, employees are calling for far more demands that employers have to fulfil (Lim, Song, \& Choi, 2012).

Avgar, Givans and Liu (2011) argue that work-life balance is no longer considered a welfare but an effective dynamic an organisation should adopt to retain its talents. The same study found a negative relationship between the existence of effective work-life policies and employees' turnover intentions. Parkes and Langford (2008) indicate that the importance of work-life balance stems from its positive impact on both individual and organisational performance, whereas Nelson, Quick, Hitt and Moesel (2012) found a positive linkage with job satisfaction. 
Moreover, Shoekand and Priyanka (2013) report a positive correlation between the work-life balance dimensions and an organisation's ability to motivate its employees.

Balancing employees' work-life is the main challenge different organisations have to manage. This may justify why 'Fortune' magazine often shows respect to organisations which assist their employees in achieving such an intended balance (Muse et al., 2008). In this regard, Rogers and Rogers (1989) define family friendly organisations as organisations which seek to enable employees to achieve balance between work and family life, whereas Redmond et al. (2006) compare work-life balance as organisational policies which intend to support employees in balancing work and family life.

As pharmacists, Egyptian females who work in governmental hospitals complain mainly about low salaries and long work hours (Mousa, 2017; Mousa \& Abdelgaffar, 2017). Mousa (2017) reported that pharmacists, regardless of their gender, are not allowed to ask for holiday due to the complete dependence on them to handle remedies to patients. Moreover, the same previously mentioned study indicated that the main challenges facing Egyptian female pharmacists is that they are required to work an uninterrupted 12 hour night or day shift (called Nobatshiya). This means no attention to these pharmacists' families, fatigue, and morale. Some female pharmacists mentioned that they have to do these night or day shifts even during official national and religious holidays. On a voluntary basis, many male pharmacists volunteer to work in place of females on such days as the feasts. Accordingly, this research seeks to focus solely on public hospitals, Menoufia province, Egypt and to fill a gap in the management literature by identifying the effect of responsible leadership on work-life balance/imbalance among female pharmacists who work there. The author starts by providing a theoretical background for responsible leadership, worklife balance/imbalance and end his theoretical discussion by formulating hypotheses. Subsequently, the research methodology is presented in which the author elaborates his research plan and present the reliability analysis for their variables, besides illustrating the profiles of their respondents. Finally, the results are presented and discussed, and the conclusions also offer suggestions for future research.

\section{LITERATURE REVIEW}

\section{Responsible Leadership}

As indicated earlier, responsible leadership is still in its infancy, and a shortage in the research addressing it is markedly noted (Maak \& Pless, 2006). Moreover, Waldman and Galvin (2008) have indicated that only after the demise of Enron and Arthur Anderson and the 2008 world economic crisis were the deficiencies of current leadership practices discovered. This prompted the emergence of responsible leadership as a dynamic to initiate social and political responsibility of businesses in addition to the political one. Furthermore, the concept of 'responsible leadership' itself is still confronting many challenges to be defined and adopted. Preez and Zyl (2015) argued that to fulfil social obligations businesses have to coordinate with different governments to achieve countries' stated goals of eradicated poverty, developed education, and accelerated economic growth, among many other different goals. This matter may not be applicable in all countries due to the burden of coordinating with governments, in addition to the bureaucracy of some governmental systems. Another main chal- 
lenge facing responsible leaders is how to balance the trade-off between maximising shareholders' profit and caring about the well-being of both shareholders and businesses they serve (Voegtlin, 2011; Pless \& Maak, 2012; Morland, 2015). Pless and Maak (2011) investigated what makes leaders responsible and how responsible leaders can be developed. On the other hand, Morgeson et al. (2010) indicate that both human resources management and organisational psychology experts can address the cultural challenge of leadership and determine the main competencies leaders need in order to be effective in fulfilling their societal responsibility. This can be undertaken when businesses start to understand carefully that the adoption of responsible leadership may provide an edge for creativity, innovation and, subsequently, competitive advantages (Preez \& Zyl, 2015).

As illustrated above, a responsible leader acts correctly on behalf of both shareholders and stakeholders. That is why he or she should have all means, capabilities, resources and authority required to attain as many benefits as possible for all parties involved (Cameron, 2011). Hymavathi et al. (2015) indicated that responsible leadership is a social phenomenon guided by moral standards. The thought falls in line with Martin Luther King's question 'what are you doing for others?'. Given what has preceded, responsible leaders should listen to different views and work closely not only with people and departments within their organisations but also with various external stakeholders, like consumer groups, governmental officials and even environmentalists (Cunha, Rego, \& Cunha, 2007).

\section{Work-life Balance}

Although Murphy and Doherty (2011) indicate that economic recession and tendency to reduce costs are considered the main reasons for the emergence of flexible work policies, especially in Europe, Gregory, Milner and Windebank (2013) consider work-life balance as an economic mechanism to raise the employment rate. Moreover, Bonoli (2005) and Anderson (1996) illustrate that supporting individuals to reconcile work and family obligations (e.g. paid employment with childcare and/or elderly care) is a priority for countries which seek welfare for their citizens. However, earlier research on work-life balance was conducted after 1990 to address, on the one hand, the importance of introducing work-life balance policies into the corporate workplace (Lee, 2005), and on the other hand, the relationship between work-life policies and some individual behaviour practices, like intentions to leave, the rate of turnover, the level of absenteeism and employee performance (Kim, 2012).

Anxo et al. (2013) highlight that designing and adopting work-life policies in a specific work setting entail an intersection for the following characteristics:

- demographic characteristics (gender, age, partner's response of collaboration),

- workplace characteristics (organisational culture, leaders' supportive tendencies, workload),

- socio-economic characteristics (the economic situation of a country, welfare policies).

As previously mentioned in the introduction, the importance of work-life balance stems from its ability to shape an employee's psychological well-being (Clark, 2000). Furthermore, in the organisational context, work-life policies have a positive relationship with employee's loyalty, performance and job satisfaction (Nelson, Quick, Hitt, \& Moesel, 1990; Cegarra-Leiva, Sanchez-Vidal, \& Cegarra-Navarro, 2012; Carlson, Witt, \& Zivnuska, 2008). Also, these policies are negatively correlated with an employee's intention to leave, turnover, absenteeism and poor performance (Anderson, 1996; Avgar et al., 2011, Mousa \& Alas, 2016; Mousa, 2017). It is clearly noted that the majority if not all of the research on work- 
life balance has been conducted in Western countries, in which individualistic interest dominates life and employees prioritise their personal goals and constantly aim to attain them usually before the goals of the organisation to which they belong (Earley, 1989).

Despite various work arrangements (e.g. part-time work, job sharing, career break, compressed hours, etc.) an organisation can undertake to assist employees in juggling their non-work activities, Drew and Murtagh (2005) pointed out that only 17 percent of senior managers employ some work arrangements to reduce their working hours and create time for non-work responsibilities. Apparently, this happens despite the advanced information technology and communication means businesses have applied over the past three decades (Eikhof, Warhust, \& Haunschild, 2007). However, a correlation between presenteeism and financial incentives is considered the main reason for managers' unwillingness to benefit from communication technology advancement and various work arrangements (Elloy \& Smith, 2003).

What is worth mentioning is the poor utilisation of family-friendly policies pertaining, in some settings, to organisational culture which considers long work hours as an indicator of an employee's organisational commitment (Drew \& Daverth, 2009). However, there is a growing tendency to shift from long hours to a results-focused approach when measuring an employee's level of performance as illustrated by Drew, Humphrey, and Murphy (2003). Feminist advocators reflect that women currently not only perform a double effort but also spend longer time at the workplace in their attempt to find a place in male-dominated societies (Straub, 2007; Mousa \& Alas, 2016). Furthermore, Drew et al. (2003) clarify that the situation is even worse when having a limited number of women at the organisational board or management level. This may be considered another struggle against the poor adoption of family-friendly initiatives in some organisational settings.

In the Egyptian society, Hofstede (1980) identifies four main characteristics constituting the Egyptian culture:

- power distance: reflects the tendency of the Egyptians to accept their leader's authority, whatever decisions he or she makes,

- uncertainty avoidance: reflects the Egyptian tendency to resist any potential change whatever its kind (political, social, etc.),

- individualism: reflects the strong power Egyptian families have in shaping an individual's behaviour,

- masculinity: reflects the superior level men have in the Egyptian society and that to a certain extent stems from Islamic religious values.

What preceded illustrates the struggle Egyptian women face not only at a societal level but also as employees. This also may justify why the UN report (2007) and Alas and Mousa (2016) mention that Egyptian women face many forms of discrimination and recommended prompt efforts to alleviate them.

\section{Responsible Leadership and Work-life Balance}

Eikhof, Warhust, and Haunschild (2007) affirm that adopting family-friendly policies in organisational setting guarantees the workplace harmony and subsequently an employee's work-life balance. Fu and Shaffer (2001) and Carnicer, Sanchez, Perez and Vela Jimenez (2003) identify the following three forms of work-life balance/imbalance that an employee may experience. 
- time-based balance/imbalance: reflects the extent to which long work hours may affect nonwork devoted time, and subsequently imbalance arises between work and non-work life,

- strain-based balance/imbalance: reflects the extent to which stress may arise as a result of an employee's attempt to reconcile work and non-work activities,

- behaviour based balance/imbalance: reflects an employee's sufferings which results from his inability to manage his behaviour and balance his work and non-work activities.

Like ethical leadership, responsible leadership fosters both individual and organisational performance (Brown \& Trevino, 2006). However, Chun (2005) indicates that the main roles of responsible leaders are building social networks with in- and- out stakeholders, listening to various viewpoints, fulfilling societal responsible obligations besides differentiating between right and wrong. That is why the scope of responsible leadership is much broader than the ethical one, which focuses only on leader-follower relationships (Pless \& Maak, 2012). To the best of the author's knowledge, no previous attempts have been made to address the effect of responsible leadership dimensions on the three forms of work life balance/imbalance. Accordingly, the following are the main hypotheses suggested by the author:

H1: Can responsible leadership dimensions (the aggregate of virtues, stakeholders' involvement, the principles of ethical values, the model of leaders' roles) affect time-based work and non-work balance/imbalance?

H2: Can responsible leadership dimensions (the aggregate of virtues, stakeholders' involvement, the principles of ethical values, the model of leaders' roles) affect strain-based work and non-work balance/imbalance?

H3: Can responsible leadership dimensions (the aggregate of virtues, stakeholders' involvement, the principles of ethical values, the model of leaders' roles) affect behaviour-based work and non-work balance/imbalance?

\section{MATERIAL AND METHODS}

To design the conceptual framework of this quantitative study, the author reviewed many previous studies conducted on either responsible leadership or work-life balance. To the best of the author's knowledge, no previous studies have focused on investigating the effect of responsible leadership dimensions on work-life balance forms. This may derive from the fact that the topic of responsible leadership is still in its embryonic stage, and not so many scholars have paid attention to it. The study was conducted on female pharmacists in Sadat city public hospitals in Menoufia (Egypt). Clearly, the focus on Sadat city public hospitals was not the main priority for the author of the present article at the first stage of his research. The intention was to include all public hospitals in Menoufia province, which is one of 27 provinces in Egypt, and to address as many female pharmacists as the author could, but unfortunately, this was not the case as the managers of Menoufia province public hospitals did not agree to cooperate either for the lack of time or for the sensitivity of the topic. Some of them consider the topic as an exposure of the country's style of leadership and the level of freedom allowed. Noticeably, Sadat city public hospitals executives reacted positively to the idea of data collection for this study. 
As previously mentioned, the major problems facing Egyptian female pharmacists in public hospitals are working on an uninterrupted 12-hour basis and an inability to ask for any holiday even during national holidays (Mousa, 2017). Consequently, they are unable to fulfil any social obligations toward their families, constantly feel stressed to create time for even their rest, and eventually feel careless towards their work and often have the tendency to leave their positions. Addressing the effect of responsible leadership, which is based on the idea of fulfilling the main interests of both internal and external stakeholders without neglecting shareholders' profit. This means that work-life balance forms may shape a mutual benefit to be achieved for both the staff and the organisations.

The number of Egyptian pharmacists who work in public hospitals in 27 Egyptian provinces is about $30.000,1.400$ of whom work in Menoufia province public hospitals. The present article focuses only on female pharmacists. Four of these female pharmacists agreed to distribute 350 questionnaire forms to their colleagues and collect them. 225 out of the 230 collected forms were valid for analysis.

As the author decided to rely on multiple regressions, an a-priori Sample Size Calculator was used to determine the minimum required sample size on which the author could depend. Given the desired probability level (0.05), the number of predictors in the model (3), the anticipated effect size (minimum 0.079), and the desired statistical power (0.8), the minimum sample size the author could utilise is 99 questionnaire forms.

The fact that all public hospitals in Sadat city have six pharmaceutical departments (intensive care pharmaceutical department, external pharmaceutical department, liver disease pharmaceutical department, country support pharmaceutical department, national insurance pharmaceutical department and internal pharmaceutical department) urged the author to employ stratified random sampling. Participants are classified into six homogenous subgroups to reduce bias and ensure valid representation. The procedures of distributing, following up and then collecting the distributed questionnaire forms extended for four weeks, and all the questionnaire forms were distributed in Arabic to motivate the participants to respond and to ensure more accurate responses.

\section{Measures}

Since research conducted on responsible leadership is still quite limited, there is no generally accepted model of responsible leadership. Accordingly, the author focused on the four dimensions (the aggregate of virtues, stakeholders' involvement, the model of leaders' roles and the principles of ethical values) of responsible leadership developed by the qualitative study of Antunes and Franco (2016). Consequently, the following are the four sections of the qualitative form created by the author of this article:

- the aggregate of virtues:

- My hospital cares about public-related aspects like education, health and poverty.

- My hospital differentiates between right and wrong.

- stakeholder involvement:

- My organisation involves in-and-out of organisation's viewpoints when making decision.

- My hospital has long lasting relationships with various stakeholders. 
- the model of leaders' role:

- My hospital respects diversity in and around it.

- My hospital considers social responsibility as a part of organisational culture.

- the principles of ethical values:

- I feel my managers are sincere when dealing with in and out stakeholders.

- My organisation accepts critique from in and out hospital stakeholders.

Table 1 presents the reliability analysis for responsible leadership challenges using Cronbach's alpha.

Table 1. Reliability analysis (responsible leadership dimensions)

\begin{tabular}{|l|c|c|}
\hline \multicolumn{1}{|c|}{ Scale name } & Number of items & Coefficient alpha values \\
\hline Responsible leadership dimensions & 8 & 0.795 \\
\hline Aggregate of virtues & 2 & 0.808 \\
\hline Stakeholder involvement & 2 & 0.810 \\
\hline Model of leader's role & 2 & 0.801 \\
\hline Principles of ethical values & 2 & 0.791 \\
\hline
\end{tabular}

Source: own study.

Work-life balance/imbalance: Despite the various approaches to work-life balance, the present study focuses on the three forms of work-life balance (time-based balance/imbalance, strain-based balance/imbalance and behaviour-based balance/imbalance) identified by Fu and Shaffer (2001) and Carnicer et al. (2003). These three forms represent the main challenges of work/non-work activities applicable to senior or management level (Murphy \& Doherty, 2011). The pharmacists in the chosen hospital are supervised by only one pharmaceutical departments manager besides the executive manager of the hospital. They have no other forms of supervision, so they are considered at a senior level. The following are the three sections of the questionnaire form distributed by the author of this article:

- time-based balance/imbalance:

o Doing my best in my work entails a reduction of time devoted to my family.

o Long work hours mean that I am a good employee.

- My hospital adopts flexible timing policy to promote work/ life balance time.

- strain-based balance/imbalance:

- I feel stressed towards my family obligations.

- I feel stressed to prove that I am a good employee and a good family member.

- My hospital encourages a smooth balance of work/ family life for me.

- behaviour-based balance/imbalance:

- My work life interferes with my family life.

o Sometimes, I face a conflict with my hospital to balance my work/ life time.

- My organisation cares only about my work time.

Table 2 is the reliability analysis for work-life balance/imbalance using Cronbach's alpha (Sekran, 2003).Table 3 shows the demographic variables of the respondents. 
Table 2. Reliability analysis for work- life balance/imbalance

\begin{tabular}{|l|c|c|}
\hline \multicolumn{1}{|c|}{ Scale name } & Number of items & Coefficient alpha values \\
\hline Work-life balance/imbalance & $\mathbf{9}$ & $\mathbf{0 . 8 7 1}$ \\
\hline Time-based balance/imbalance & 3 & 0.822 \\
\hline Strain-based balance/imbalance & 3 & 0.809 \\
\hline Behaviour-based balance/imbalance & 3 & 0.702 \\
\hline
\end{tabular}

Source: own study.

Table 3. Profile of the respondents

\begin{tabular}{|c|c|c|}
\hline Demographic variables & Items & Count \\
\hline \multirow{2}{*}{ a) Gender } & Male & 0 \\
\hline & Female & 225 \\
\hline \multirow{7}{*}{ b) Age } & below 25 years & 19 \\
\hline & $26-30$ years & 150 \\
\hline & $31-35$ years & 51 \\
\hline & $36-40$ years & 5 \\
\hline & $41-45$ years & 0 \\
\hline & $46-50$ years & 0 \\
\hline & More than 50 years & 0 \\
\hline \multirow{3}{*}{ c) Marital States } & Single & 70 \\
\hline & Married & 125 \\
\hline & Other & 30 \\
\hline \multirow{3}{*}{ d) Level of Education } & Bachelor & 15 \\
\hline & Bachelor + Diploma & 200 \\
\hline & Master & 10 \\
\hline \multirow{5}{*}{ e) Level of Income } & EGP 1200 & 0 \\
\hline & EGP $1300-2500$ & 225 \\
\hline & EGP 2500-4000 & 0 \\
\hline & EGP 4000-5500 & 0 \\
\hline & Above 5500 & 0 \\
\hline \multirow{6}{*}{ f) Organisational tenure } & Less than 1 year & 5 \\
\hline & $1-3$ years & 20 \\
\hline & 4-6 years & 200 \\
\hline & $7-9$ years & 0 \\
\hline & $10-12$ years & 0 \\
\hline & Above 15 years & 0 \\
\hline \multirow{2}{*}{ g) Religion } & Muslim & 200 \\
\hline & Christian & 25 \\
\hline \multirow{2}{*}{ h) Work Bases } & Full time & 225 \\
\hline & Part time & 0 \\
\hline
\end{tabular}

Source: own study.

\section{RESULTS AND DISCUSSION}

The main purpose of this research is to understand how much of the variation in time, strain and behaviour-based balance/imbalance can be explained by responsible leadership dimensions (the aggregate of virtues, stakeholder involvement, the model of leader's role and the 
principles of ethical values). The use of multiple regression analysis assists in understanding the unique contribution of each of the responsible leadership dimensions.

Testing the research hypotheses is necessary to validate the hierarchical multiple regression analysis. In order to evaluate the regression models in the hierarchical multiple regressions in the present study, four models were used. In the first model, the independent variable is the Aggregate of virtues and the three elements of Work-life balance/imbalance will be used as separated dependent variables. In the second model, the independent variables are the Aggregate of virtues and Stakeholder involvement. Notably, the second Model is not a completely separate model but a variation of Model 1 with one variable added. In the third model, the independent variables are the Aggregate of virtues, Stakeholder involvement and the Model of leaders' role. And finally in the fourth model, the independent variables are the Aggregate of virtues, Stakeholder involvement, the Model of leaders' role and the Principles of ethical values.

Each model is a standard multiple regression procedure with the variables in that model entered simultaneously. Therefore, each model has measures which show how well that particular model fits the data, and these are presented in Table 4.

Table 4. Summary of the regression analyses of the models

\begin{tabular}{|c|c|c|c|c|c|c|c|c|c|c|}
\hline Var. & Model & $\mathbf{R}$ & $\begin{array}{c}\mathbf{R} \\
\text { Square }\end{array}$ & $\begin{array}{l}\text { Adjusted } \\
\text { R Square }\end{array}$ & $\begin{array}{l}\text { Std. Error of } \\
\text { the Estimate }\end{array}$ & $\begin{array}{l}\text { R Square } \\
\text { Change }\end{array}$ & $\mathbf{F}$ & df1 & df2 & $\begin{array}{l}\text { Sig. F } \\
\text { Change }\end{array}$ \\
\hline \multirow{4}{*}{ D1 } & 1 & 0.653 & 0.613 & 0.619 & 7.20155 & 0.613 & 11.994 & 1 & 223 & 0.000 \\
\hline & 2 & 0.769 & 0.725 & 0.687 & 4.19765 & 0.112 & 41.496 & 1 & 222 & 0.000 \\
\hline & 3 & 0.797 & 0.763 & 0.752 & 7.19238 & 0.038 & 49.230 & 1 & 221 & 0.003 \\
\hline & 4 & 0.833 & 0.804 & 0.780 & 7.18390 & 0.041 & 52.469 & 1 & 220 & 0.000 \\
\hline \multirow{4}{*}{ D2 } & 1 & 0.067 & 0.004 & 0.004 & 0.20268 & 0.004 & 0.507 & 1 & 223 & 0.067 \\
\hline & 2 & 0.711 & 0.692 & 0.676 & 3.20277 & 0.692 & 35.900 & 1 & 222 & 0.000 \\
\hline & 3 & 0.834 & 0.795 & 0.762 & 2.14560 & 0.103 & 40.219 & 1 & 221 & 0.000 \\
\hline & 4 & 0.897 & 0.850 & 0.843 & 7.13214 & 0.055 & 42.757 & 1 & 220 & 0.000 \\
\hline \multirow{4}{*}{ D3 } & 1 & 0.667 & 0.624 & 0.604 & 8.20268 & 0.624 & 20.507 & 1 & 223 & 0.000 \\
\hline & 2 & 0.741 & 0.720 & 0.695 & 5.20277 & 0.096 & 34.900 & 1 & 222 & 0.000 \\
\hline & 3 & 0.794 & 0.785 & 0.762 & 10.14560 & 0.062 & 43.219 & 1 & 221 & 0.000 \\
\hline & 4 & 0.827 & 0.808 & 0.783 & 9.13214 & 0.023 & 50.757 & 1 & 220 & 0.767 \\
\hline
\end{tabular}

Note: D1, D2 and D3 are the dependent variables which are the three aspects of Work-life balance/imbalance. D1 = time-based balance/imbalance; D2 = strain-based balance/imbalance; D3 = behaviour-based balance/imbalance Source: own study.

The most important measurement used to interpret a hierarchical multiple regression is $\mathrm{R} 2$, which represents the variation in the dependent variable explained by the independent variables. The results show that each model explains a greater amount of the variation in the dependent variable as more variables are added. Essentially, the models here get better at predicting the dependent variable.

In the case of the dependent variable Time-based balance/imbalance in Model 1, in which the Aggregate of virtues alone is the independent variable, R2 is 0.613 , with statistical significance of $p<0.005$. Due to the inclusion of Stakeholder involvement as an additional independent variable, R2 increased by 0.0112 (the variance explained increased by $11.2 \%)$, and this increase is statistically significant $(p<0.0005)$ and $F$ increased to 41.496. In other words, Stakeholder involvement adds statistical significance 
to the prediction of the Aggregate of virtues. In sum, the addition of Stakeholder involvement to the prediction of the Aggregate of virtues (Model 2) led to a statistically significant increase in R2 of 0.0112 and $F(1.222)=41.496, p<0.0005$.

In the third Model, where the Model of leaders' role is added as independent variable, R2 increases by 0.038 (the variance explained increased by $3.8 \%$ ), and this increase is statistically significant $(p<0.0005)$. In sum, the addition of the Model of leaders' role to the prediction of the Aggregate of virtues (Model 3) led to a statistically significant increase in R2 of 0.038 and $F(1.221)=49.230, p<0.0005$.

With regard to the last Model (4), where the Principles of ethical values is added as an independent variable, R2 increases by 0.041 (the variance explained increased by $4.1 \%$ ), and this increase is statistically significant $(p<0.0005)$. Thus, the addition of the Principles of ethical values to the prediction of the Aggregate of virtues (Model 4) brought about a statistically significant increase in R2 of 0.041 and $F(1.220)=52.469, p<0.0005$.

In the case of the dependent variable Strain-based balance/imbalance in Model 1 , in which the Aggregate of virtues stands alone, there is no statistical significance of $p<0.005$. Due to the inclusion of Stakeholder involvement as an additional independent variable, R2 is 0.692 , and this increase is statistically significant $(p<0.0005)$ and $F=35.900$. In other words, Stakeholder involvement adds statistical significance to the prediction of the Aggregate of virtues. In the third Model where the Model of leaders' role is added as an independent variable, R2 increased by 0.103 (the variance explained increased by $10.3 \%$ ), and this increase is statistically significant ( $p<$ $0.0005)$. Therefore, the addition of the Model of leaders' role to the prediction of the Aggregate of virtues (Model 3 ) has resulted in a statistically significant increase in R2 of 0.103 and $F(1.221)=40.2190, p<0.0005$.

Concerning the last Model (4), where the Principles of ethical values is added as an independent variable, R2 increased by 0.055 (the variance explained increased by $5.5 \%$ ), and this increase is statistically significant $(p<0.0005)$. Hence, the addition of the Principles of ethical values to the prediction of the Aggregate of virtues (Model 4) led to a statistically significant increase in R2 of 0.055 and $F(1.220)=42.757, p<0.0005$.

In the case of the dependent variable Behaviour-based balance/imbalance in Model 1, in which the Aggregate of virtues alone is the independent variable, $R$ is 0.624 , with statistical significance of $p<0.005$. Due to the inclusion of Stakeholder involvement as an additional independent variable, R2 increased by 0.96 (the variance explained increased by $9.6 \%)$, and this increase is statistically significant $(p<0.0005)$ and $F$ increased to 34.900. In other words, Stakeholder involvement adds statistical significance to the prediction of the Aggregate of virtues. As a result, the addition of Stakeholder involvement to the prediction of the Aggregate of virtues (Model 2) also led to a statistically significant increase in R2 of 0.096 and $F(1.222)=34.900, p<0.0005$.

In the third Model, where the Model of leaders' role is added as an independent variable, R2 increased by 0.062 (the variance explained increased by $6.2 \%$ ), and this increase is statistically significant $(p<0.0005)$. In summary, the addition of the Model of leaders' role to the prediction of the Aggregate of virtues (Model 3) brought about a statistically significant increase in $\mathrm{R} 2$ of 0.062 and $F(1.221)=43.219, \mathrm{p}<0.0005$. 
In the last Model (4), where the Principles of ethical values is added as an independent variable, R2 increased by 0.023 (the variance explained increased by $2.3 \%$ ), and this increase is statistically significant $(p<0.0005)$. As such, the addition of the Principles of ethical values to the prediction of the Aggregate of virtues (Model 4) resulted in a statistically significant increase in $R 2$ of 0.023 and $F(1.220)=50.757, p<0.0005$.

Table 5. Hierarchical Multiple Regression predicting Time-based balance/imbalance as an element of Work - life balance/imbalance from the Aggregate of virtues, Stakeholder involvement, the Model of leaders' role and the Principles of ethical values

\begin{tabular}{|c|c|c|c|c|c|c|c|c|}
\hline \multicolumn{3}{|r|}{ Var. } & B & $\beta$ & R2 & $\mathbf{F}$ & $\Delta \mathrm{R} 2$ & $\Delta \mathrm{F}$ \\
\hline & \multirow{2}{*}{ Model 1} & (Constant) & 2.090 & & 0.613 & 11.994 & 0.613 & 11.994 \\
\hline & & Aggregate of virtues & 0.425 & 0.388 & & & & \\
\hline & \multirow{3}{*}{ Model 2} & (Constant) & 2.450 & & 725 & 30.425 & 0.687 & 41.496 \\
\hline & & Aggregate of virtues & 0.405 & 0.368 & & & & \\
\hline & & Stakeholder involvement & 0.232 & 0.199 & & & & \\
\hline & \multirow{4}{*}{ Model 3} & (Constant) & 3.151 & & 0.763 & 35.003 & 0.752 & 49.230 \\
\hline \multirow{7}{*}{1} & & Aggregate of virtues & 0.435 & 0.409 & & & & \\
\hline & & Stakeholder involvement & 0.367 & 0.309 & & & & \\
\hline & & Model of leaders' role & 0.250 & 0.193 & & & & \\
\hline & \multirow{5}{*}{ Model 4} & (Constant) & 2.115 & & 0.804 & 45.054 & 0.780 & 52.469 \\
\hline & & Aggregate of virtues & 0.483 & 0.440 & & & & \\
\hline & & Stakeholder involvement & 0.373 & 0.324 & & & & \\
\hline & & Model of leaders' role & 0.268 & 0.219 & & & & \\
\hline & & Principles of ethical values & 0.177 & 0.122 & & & & \\
\hline
\end{tabular}

Note: $N=225 ; p<0.05$

Source: own study.

Table 6. Hierarchical Multiple Regression predicting Strain-based balance/imbalance as an element of Work-life balance/imbalance from the Aggregate of virtues, Stakeholder involvement, the Model of leaders' role and the Principles of ethical values

\begin{tabular}{|c|c|c|c|c|c|c|c|c|}
\hline & & Var. & B & $\beta$ & $\mathbf{R}^{2}$ & $\mathbf{F}$ & $\Delta \mathbf{R}^{2}$ & $\Delta \mathrm{F}$ \\
\hline & Model 1 & (Constant) & 4.403 & & 0.004 & 0.507 & 0.004 & 0.507 \\
\hline & |ivioder I & Aggregate of virtues & 0.027 & 0.067 & & & & \\
\hline & & (Constant) & 4.668 & & 0.692 & 25.703 & 0.676 & 35.900 \\
\hline & Model 2 & Aggregate of virtues & 0.036 & 0.027 & & & & \\
\hline & & Stakeholder involvement & 0.496 & 0.391 & & & & \\
\hline & & (Constant) & 5.023 & & 0.795 & 36.316 & 0.762 & 40.219 \\
\hline & & Aggregate of virtues & 0.122 & 0.098 & & & & \\
\hline DL & Jiodel 3 & Stakeholder involvement & 0.497 & 0.382 & & & & \\
\hline & & Model of leaders' role & 0.427 & 0.388 & & & & \\
\hline & & (Constant) & 4.840 & & 0.850 & 39.255 & 0.843 & 42.757 \\
\hline & & Aggregate of virtues & 0.171 & 0.073 & & & & \\
\hline & Model 4 & Stakeholder involvement & 0.391 & 0.376 & & & & \\
\hline & & Model of leaders' role & 0.408 & 0.386 & & & & \\
\hline & & Principles of ethical values & 0.387 & 0.327 & & & & \\
\hline
\end{tabular}

Note: $N=225 ; p<0.05$

Source: own study. 
Table 7. Hierarchical Multiple Regression predicting Behaviour-based balance/imbalance as an element of Work - life balance/imbalance from the Aggregate of virtues, Stakeholder involvement, the Model of leaders' role and the Principles of ethical values

\begin{tabular}{|c|c|c|c|c|c|c|c|c|}
\hline \multicolumn{3}{|r|}{ Var. } & B & $\beta$ & R2 & $\mathbf{F}$ & $\Delta \mathbf{R 2}$ & $\Delta \mathbf{F}$ \\
\hline \multirow{14}{*}{ D3 } & \multirow{2}{*}{ Model 1} & (Constant) & 2.477 & & 0.624 & 20.507 & 0.604 & 20.507 \\
\hline & & Aggregate of virtues & 0.196 & 0.165 & & & & \\
\hline & \multirow{3}{*}{ Model 2} & (Constant) & 2.724 & & 0.720 & 30.778 & 0.695 & 34.900 \\
\hline & & Aggregate of virtues & 0.288 & 0.252 & & & & \\
\hline & & Stakeholder involvement & 0.390 & 0.260 & & & & \\
\hline & \multirow{4}{*}{ Model 3} & (Constant) & 4.558 & & 0.785 & 37.187 & 0.762 & 43.219 \\
\hline & & Aggregate of virtues & 0.285 & 0.177 & & & & \\
\hline & & Stakeholder involvement & 0.376 & 0.251 & & & & \\
\hline & & Model of leaders' role & 0.426 & 0.381 & & & & \\
\hline & \multirow{5}{*}{ Model 4} & (Constant) & 3.586 & & 0.808 & 45.870 & 0.783 & 50.757 \\
\hline & & Aggregate of virtues & 0.214 & 0.197 & & & & \\
\hline & & Stakeholder involvement & 0.352 & 0.235 & & & & \\
\hline & & Model of leaders' role & 0.299 & 0.181 & & & & \\
\hline & & Principles of ethical values & 0.431 & 0.391 & & & & \\
\hline
\end{tabular}

Note: $N=225 ; p<0.05$

Source: own study.

Hierarchical multiple regressions are run to determine if the addition of three more variables: Stakeholder involvement, the Model of leaders' role, the Principles of ethical values as part of Responsible Leadership would improve the prediction of Timebased balance/imbalance over and above the Aggregate of virtues. The full model of Responsible Leadership and Work-life balance/imbalance for predicting Time-based balance/imbalance (Model 4 ) is found to be statistically significant $-\mathrm{R} 2=0.804$, $\mathrm{F}(1.220)=45.054 .433, \mathrm{p}<0.0005$, and adjusted $\mathrm{R} 2=0.780$.

Hierarchical multiple regressions are run to determine if the addition of Stakeholder involvement, the Model of leaders' role, the Principles of ethical values as part of Responsible Leadership would improve the prediction of Strain-based balance/imbalance over and above the Aggregate of virtues, as the Aggregate of virtues is not statistically significant for this model. The full model of Responsible Leadership and Work-life balance/imbalance for predicting Strain-based balance/imbalance (Model 4) is statistically significant $-\mathrm{R} 2=0.850 \mathrm{~F}(1.220)=39.255, \mathrm{p}<0.0005 ;$ adjusted $\mathrm{R} 2=0.843$.

Hierarchical multiple regressions are run to determine whether the addition of involvement, the Model of leaders' role, the Principles of ethical values as part of Responsible Leadership - would improve the prediction of Behaviour-based balance/imbalance over and above the Aggregate of virtues. The full model of Responsible Leadership and Work-life balance/imbalance for predicting Behaviour-based balance/imbalance (Model 4) is statistically significant $-\mathrm{R} 2=0.808 \mathrm{~F}(1.220)=45.870, \mathrm{p}<0.0005$; adjusted $\mathrm{R} 2=0.783$.

The importance of this topic pertains to the recent changes in the Egyptian labour market which occupy a tremendous space not only in the Egyptian social discourse but also in various international social media outlets. The Egyptian labour market in which men used to have superiority, authority and domination has lately witnessed an increasing active partici- 
pation of Egyptian women, especially with an increasing number of success stories of Egyptian female managers, entrepreneurs and executives in both public and private organisations (Mousa \& Abdelgaffar, 2017). It is obvious that masculinity-oriented tendency, uncertain work environment, changing job roles, and social class discrimination that many Egyptians face did not curb Egyptian women from penetrating the labour market there.

The research unit of this current study is female pharmacists, and the research place is public hospitals in Menoufia province in Egypt. This study was inspired by the results of Mousa (2017) which convey the suffering experienced by Egyptian female nurses working in the Egyptian public health sector. The interviews included in this study assert that Egyptian female nurses struggle due to long working hours, male domination, and work overload because of their small number and/or the desire to prove themselves in the male-dominant society. This study is mostly about discrimination and managing cultural diversity in the Egyptian public health sector and it touches on the challenges of balancing work and non-work activities and time. In the present study, the author found it a very pioneering attempt to address the marginalisation of females in the Egyptian public sector. The present study, thus, focuses on investigating the effect of responsible leadership dimensions (the aggregate of virtues, stakeholder engagement, and leader-followers model) on three forms of work-life balance/imbalance among the female pharmacists in Menoufia public hospitals (Egypt).

The first hypothesis of the present study is whether responsible leadership dimensions affect time based balance/imbalance, and the results show that only the aggregate virtue has a significant effect on time-based balance/imbalance. This result seems logical because the main philosophy of the aggregation of virtue is to urge organisational leaders to fulfil their socio-political responsibility towards their surrounding environment. This result is a valid contribution to the general public with respect to areas such as education, health, and supporting people with disabilities. In this case study, female pharmacists, as reported in the conducted interviews, work 12 hours a day, and thus cannot be expected to manage their non-work activities and cannot devote time to discuss or promote their hospitals' care towards public well-being, which is the main aim of the aggregate virtue.

The same can be said about the results of testing the second hypothesis which showed that all dimensions of responsible leadership affect strain-based balance/imbalance except the aggregate of virtues. This result sounds logical also as what a hospital or a workplace is doing for others in its surroundings might not be an urgent concern for female pharmacists who mainly struggle to find time for their social and family obligations. The results of the third hypothesis indicate that the aggregate of virtue is not considered a significant statistical predictor of female pharmacists' behaviour-based balance/imbalance. Consequently, neither would the hospital be able to undertake its social responsibilities, nor would it be able to support female pharmacists' tendency and subsequently attempts to balance their work/non-work activities.

The previous results reflect that female pharmacists cannot be considered an active participant in calling for or contributing to the general well-being of their surrounding stakeholders without having the means, resources and authority required to encourage their workplace to handle its responsibilities as indicated by Cameron (2011). Additionally, female pharmacists will not think about others without having attained their psychological self-actualisation first. Such psychological self-actualisation involves having reasonable work hours, a relevant level of performance, sufficient days off and 
holiday, and mostly persuasive open work-related communications as well. Given the previous results, the author of the present study unintentionally found himself raising the questions concerning when and to what extent female pharmacists should motivate their leaders to undertake their societal objectives and whether there is any opportunity in such a climate of stress to think about public-related aspects.

Needless to say, the results of the present study encourage management academicians and practitioners to look for the main conditions required for the effective adoption of responsible leadership in the Egyptian public context. Moreover, the same can be said about work-life balance which is considered by Andersen (2000) as a priority for countries which seek welfare for their citizens. Accordingly, one could ask about the efficacy of the current socio-political climate that Egypt is witnessing and the role of this climate in motivating public organisations like hospitals to address the forms of worklife balance/imbalance in their human resources management agenda.

\section{CONCLUSIONS}

Apparently, employees' attitude towards societal integration and subsequently citizenship would not be attained without a feeling of fairness and inclusion in their workplace. Many studies (e.g., Pless, 2007; Mousa, 2017) have discussed the importance of equal employment opportunity approach in recruiting employees. However, the approach of equal employment should expand to cover assisting employees, especially females, in balancing their work/nonwork activities. In Egypt, the view of seeing the man as the sole breadwinner of the family should be shifted to reflect the current existence of woman in workplace. Accordingly, organisational elites should create a mechanism to consider female work-life balance as a part of Egyptian public policy. Consequently, public organisations like hospitals have to treat women pharmacists responsively as the main part of stakeholders who are in need for flexible work hours, active participation in decision making, and clear empowerment in workplace. Logically, previous needs of female pharmacists are included within the scope of responsible leadership dimensions. Unfortunately, a lot of uncertainty exists, concerning their real adoption in the Egyptian public health organisations. In fact, it is the time for the whole society to re-evaluate the current style of leadership and its implications in aspects such as female work-life balance in different organisational settings.

In conclusion, this study investigates whether responsible leadership dimensions can affect female pharmacists' work-life balance/imbalance in public hospitals in Menoufia province, Egypt. This research may be subject to criticism because it focuses only on a single Egyptian province - a matter that does not give way to a variety of views. Furthermore, the author overlooked some moderating variables, such as the pharmacists' engagement, inclusion, job autonomy and so on.

For future studies, the author suggests testing the same propositions with physicians, nurses, and other categories of employees in Egyptian public hospitals. Moreover, a qualitative interdisciplinary study is urgently needed to identify the existence of responsible leadership in the Egyptian public health sector. Furthermore, a multi-disciplinary study for scholars from fields likes organisational psychology, organisational communication, human resources management, public administration, public policy and cultural diversity management is also needed to propose a mechanism to balance female pharmacists' work/non-work activities and to find solutions for the double amount of 
time and effort required from them in performing their job roles. Finally the same hypotheses of this study should be tested in other private and non-for profits Egyptian organisations to explore the female work/life situations there as well.

\section{REFERENCES}

Alas, R., \& Mousa, M. (2016). Cultural diversity and business schools' curricula: a case from Egypt, Problems and Perspectives in Management, 14(2), 130-137. https://doi.org/10.21511/ppm.14(2-1).2016.01

Anderson, C.D. (1996). Understanding the inequality problematic: from scholarly rhetoric to theoretical reconstruction. Gender and Society, 10, 729-746.

Antunes, A., \& Franco, M. (2016). How people in organizations make sense of responsible leadership practices. Multiple case studies. Leadership \& Organization Development Journal, 37(1), 126152. https://doi.org/10.1108/LODJ-04-2014-0084

Anxo, D., Franz, C., \& Kummerling, A. (2013). Working in time and work- life balance in a life course perspective. European Foundation for the Improvement of Living And Working Conditions, Dublin.

Avgar, A.C., Givan, R.K., \& Liu, M. (2011). A balancing act: work- life balance and multiple stakeholder outcomes in hospitals. British Journal of Industrial Relations, 49(4), 717-741. https://doi.org/10.1111/j.1467-8543.2010.00839.x

Avram, D.O., \& Kuhne, S. (2008). Implementing responsible business behaviour from a strategic management perspective: Developing a framework for Austrian SMEs. Journal of Business Ethics, 82(2), 463-475. https://doi.org/10.1007/s10551-008-9897-7

Bonoli, G. (2005). The politics of the new social policies: providing coverage against new social risks in mature welfare states. Policy and Politics, 33(3), 431-449.

Brown, R., Charnsangavej, T., Kenough, K.A., Newan, M.L., \& Rentfrow, P. (2000). Putting the affirm into affirmative action: preferential selection and academic performance. Journal of Personality and Social Psychology, 79(5), 736-747.

Cameron, K. (2011). Responsible leadership as virtuous leadership. Journal of Business Ethics, 98(1), 25-35.

Carlson, D.S., Witt, L.A., \& Zivnuska, S. (2009). Is work-family balance more than conflict and enrichment?. Human Relations, 62(10), 1459-1468.

Carnicer, M., Sanchez, A.M., Perez, M.P., \& Vela Jimenez, M.J. (2003). Gender differences of mobility: analysis of job and work-family factors. Women in Management Review, 18(4), 199-219. https://doi.org/10.1108/09649420310479408

Carrasco, I. (2007). Corporate social responsibility, values and cooperation. International Advances in Economic Research, 13(4), 454-460.

Cegarra-Leiva, D., Sanchez-Vidal, M.E., \& Cegarra-Navarro, J.G. (2012). Understanding the link between work life balance practices and organizational outcomes in SMEs. Personnel Review, 41(3), 359-379.

Ciculla, J.B. (2004). Ethics and leadership effectiveness. In J. Antonakis, A.T. Cianciola, \& R.J. Sternberg (Eds.), The Nature of Leadership (pp. 302-328), CA: Sage Publications, Thousand Oaks.

Clark, S.C. (2000). Work/family border theory: a new theory of work/ family balance. Human Relations, 53(6), 747-770. https://doi.org/10.1177/0018726700536001

Cunha, M., Rego, A., \& Cunha, R. (2007). Positive Organizations. Lisbon: Dom Quixote.

De Hoogh, A.H., \& Den Hartog, D.N. (2008). Ethical and despotic leadership, relationships with leader's social responsibility, top management team effectiveness and subordinates' optimism: a multi- method study. The Leadership Quarterly, 19(3), 297-314. https://doi.org/10.1016/j.leaqua.2008.03.002 
Drew, E., \& Daverth, G. (2009). Living together... or working to live? The role of managers in creating work-life balance in Ireland. ICTU Briefing Paper (pp. 1-27), Dublin.

Drew, E., \& Murtagh, E.M. (2005). Work/life balance: senior management champions or laggards?. Women in Management Review, 20(4), 262-278. https://doi.org/10.1108/09649420510599089

Drew, E., Humphrey, P., \& Murphy, C. (2003). Off the treadmill-achieving work/life balance. The National Framework Committee for Work/Life Balance Policies.

Earley, P.C. (1989). Social loafing and collectivism: a comparison of the United States and the People's Republic of China. Administrative Sciences Quarterly, 34(4), 565-581.

Eikhof, D.R., Warhust, C., \& Haunschild, A. (2007). Introduction: what work? What life? What balance? Critical reflections on the work- life balance debate. Employee Relations, 29(4), 325-333. https://doi.org/10.1108/01425450710839452

Elloy, D.F., \& Smith, C.R. (2003). Patterns of stress, work-family conflict, role conflict, role ambiguity and overload among dual-career and single-career couples: an Australian study. Cross Cultural Management, 10(1), 55-66. https://doi.org/10.1108/13527600310797531

Emslie, C., \& Hunt, K. (2009). Live to work or work to live? A qualitative study of gender and worklife balance among men and women in mid-life. Gender, Work and Organization, 16(1), 151172. https://doi.org/10.1111/j.1468-0432.2008.00434.x

Erkutlu, H., \& Chafra, J. (2016). Benevolent leadership and psychological well-being: the moderating effects of psychological safety and psychological contract breach. Leadership \& Organization Development Journal, 37(3), 369-386. https://doi.org/10.1108/LODJ-07-2014-0129

Eva, N., \& Sendjaya, S. (2013). Creating future leaders: an examination of youth leadership development in Australia. Education and Training, 55(6), 584-598. https://doi.org/10.1108/ET-08-2012-0082

Fishbein, M., \& Ajzen, I. (1975). Belief, Attitude, Intention and Behaviour: An Introduction to Theory and Research. Ontario: Addison-Wesley Pub. Co.

Frone, M.R., Yardley, J.K., \& Markel, K.S. (1997). Developing and testing an integrative model of work-family interface. Journal of Vocational Behaviour, 50, 145-167. https://doi.org/10.1006/jvbe.1996.1577

Fu, C., \& Shaffer, M. (2001). The tug of work and family: direct and indirect domain-specific determinants of family interference with work and work interference with family. Personnel Review, 30(1), 502-522. https://doi.org/10.1108/EUM0000000005936

Gregory, A., Milner, S., \& Windebank, J. (2013). Work-life balance in times of economic crisis and austerity. International Journal of Sociology and Social Policy, 33(9/10), 528-541. https://doi.org/10.1108/IJSSP-05-2013-0061

Harr, J., \& Spell, C. (2004). Programme knowledge and value of work. Family practice and organizational commitment. The International Journal of Human Resources Management, 15(6), 10401055. https://doi.org/10.1080/09585190410001677304

Hennig, M., Gaterman, D., \& Hagglund, A.E. (2012). Pros and cons of family of family policies for mother's labour market participation. International Journal of Sociology and Social Policy, 32 (9/10), 502-512.

Hofstede, G., \& Hofstede, G.J. (2005). Cultures and organizations: software of the mind. McGraw Hill.

Holt, R. (2006). Principles and practice: Rhetoric and the moral character of managers. Human Relations, 59(2), 1659-1680. https://doi.org/10.1177/0018726706072867

Hymavathi, Ch.L., Kasarabada, A., \& Avadhanam, S. (2015). Demonstrating responsible leadership at SOS Villages-A real case. International Journal on Leadership, 3(2), 1-6.

Inglehart, R. (2008). Changing values among western publics from 1970 to 2006. West European Politics, 31(1-2), 130-146. https://doi.org/10.1080/01402380701834747 
Kim, H.K. (2014). Work-life balance and employees' performance: the mediating role of affective commitment. Global Business and Management Research: An International Journal, 6(1), 37-51.

Kim, S.M. (2012). A study on women resources utilization: introduction of work-life balance policy, unpublished master's thesis, Keimyung University, Korea.

Lee, Y.H. (2005). The effect of work-life practices on the job pursuit intentions, unpublished master's thesis, Joongang University, Korea.

Lim, D.H., Song, J.H., \& Choi, M. (2012). Work-family interface: effect of enrichment and conflict on job performance of Korean workers. Journal of Management and Organization, 18(3), 383-397. http://dx.doi.org/10.5172/jmo.2012.18.3.383

Maak, T., \& Pless, N.M. (2006). Responsible leadership in a stakeholder society- A relational perspective. Journal of Business Ethics, 66(1), 99-115. https://doi.org/10.1007/s10551-006-9047-z

Maak, T., \& Pless, N.M. (2009). Business leaders as citizens of the world. Advancing humanism on a global scale. Journal of Business Ethics, 88(3), 537-550. https://doi.org/10.1007/s10551-009-0122-0

Morland, M.P. (2015). Philosophical assumptions undermining responsible management education. Journal of Management Development, 34(1), 61-75. https://doi.org/10.1108/JMD-06-2014-0060

Mousa, M., \& Abdelgaffar, H.A. (2017). A float over uncertainty and cynicism: an experience from Egypt. Journal of Commerce and Management Thought, 8(3), 508-530.

Mousa, M., \& Alas, R. (2016). Cultural diversity and organizational commitment: A study on teachers of primary public schools in Menoufia (Egypt). International Business Research 9(7), 154-163. https://doi.org/10.5539/ibr.v9n7p154

Mousa, M., \& Alas, R. (2016). Uncertainty and organizational commitment: a study on primary public schools' teachers in Menoufia (Egypt). European Journal of Business and Management 8(20), 38-47.

Mousa, M. (2017). Clouds over Egypt: Culture Traits and Organizational Commitment in Public Education. International Journal of Education and Management Studies, 7(2), 251-258.

Mousa, M. (2017). How do nurses perceive their cultural diversity? An exploratory case study. African Journal of Business Management, 11(17), 446-455. https://doi.org/10.5897/AJBM2017.8363

Morgeson, F.P., Dierdorff, E.C., \& Hmurovic, J.L. (2010). Work design in situ: Understanding the role of occupational and organizational context. Journal of Organizational Behavior, 31, 351-360. https://doi.org/10.1002/job.642

Murphy, F., \& Doherty, L. (2011). The experience of work life balance for Irish senior managers. Equality, Diversity and Inclusion: An International Journal, 30(4), 252-277. https://doi.org/10.1108/02610151111135732

Muse, L., Harris, S.G., Giles, W.E., \& Feild, H.S. (2008). Work-life benefits and positive organizational behavior: is there a connection?. Journal of Organizational Behavior, 29, 171-192. https://doi.org/10.1002/job.506

Nelson, D.L., Quick, J.C., Hitt, M.A., \& Moesel, D. (1990). Politics, lack of career progress and work/home conflict: stress and strain for working women. Sex Roles, 23(3-4), 169-185. https://doi.org/10.1007/BF00289864

Nonet, G., Kassel, K., \& Meijs, L. (2016). Understanding responsible management: Emerging themes and variations from European business school programs. Journal of Business Ethics, 139, 717736. https://doi.org/10.1007/s10551-016-3149-z

Parkes, L.P., \& Langford, P.H. (2008). Work-life balance or work-life alignment? A test of the importance of work-life balance for employee engagement and intention to stay in organizations. Journal of Management and Organization, 14(3), 267-284. https://doi.org/10.5172/jmo.837.14.3.267

Pless, N.M., \& Maak, T. (2011). Responsible leadership: Pathways to the future. Journal of Business Ethics, 98, 3-13. https://doi.org.10.1007/s10551-011-1114-4 
Pless, N.M., Maak, T., \& Waldman, D.A. (2012). Different approaches toward doing the right thing: mapping the responsibility orientations of leaders. Asia Pacific Journal of Management, 26(4), 451-465.

Pless, N.M. (2007). Understanding responsible leadership: role identity and motivational drivers. Journal of Business Ethics, 74(4), 437-456. https://doi.org.10.1007/s10551-007-9518-x

Preez, R.D., \& Zyl, L.T.V. (2015). Toward the development of a corporate social responsibility leadership questionnaire: an adaptation of the LB1-2. SA Journal of Industrial Psychology, 41(1), 1-18. https://doi.org/10.4102/sajip.v41i1.1256

Redmond, J., Valiulis, M., \& Drew, E. (2006). Literature Review on Issues of Work Life Balance, Workplace Culture and Maternity/Childcare Issues. Dublin: Ireland Crisis Pregnancy Agency.

Sekaran, U. (2003). Research methods for business. A skill building approach (4th Ed.). New York: John Wiley and Sons.

Sharma, S., Parmar, J.S., \& Chauhan, S.S. (2016). Work-related variables and work-life balance - A study on nurses in government hospitals of Himachal Pradesh. Productivity, 57(3), 286-292.

Sheokand, K.S., \& Priyanka (2013). Work life balance: an overview of Indian companies. International Journal of Research in Commerce And Management, 4(1), 138-143.

Tran, D.M., Fallon, W., \& Vickers, M.H. (2016). Leadership in Vietnamese state owned enterprises (SOEs) exploring multi-stakeholder perceptions - a qualitative study. Asia Pacific Journal of Business Administration, 8(1), 21-36. https://doi.org/10.1108/APJBA-10-2014-0116

Voegtlin, C. (2011). Development of a scale measuring discursive responsible leadership. Journal of Business Ethics, 98(1), 57-73.

Wade, M. (2006). Developing leaders for sustainable business. In T. Maak \& N.M. Pless (Eds.), Responsible Leadership (pp. 227-244). London: Routledge.

Waldman, D.A., \& Galvin, B.M. (2008). Alternative perspectives of responsible leadership. Organizational Dynamics, 37(4), 327-341.

Waldman, D.A., \& Siegel, D. (2008). Defining the socially responsible leader. The Leadership Quarterly, 19(1), 117-131. https://doi.org.10.1016/j.leaqua.2007.12.008

Wang, S., Huang, W., Gao, Y., Ansett, S., \& Xu, S. (2015). Can socially responsible leaders drive Chinese firm performance?. Leadership \& Organization Development Journal, 36(4), 435-450. https://doi.org/10.1108/LODJ-01-2014-0006 


\section{Author}

\section{Mohamed Mousa}

Mohamed Mousa is a Post Doctorate researcher at Cardiff School of Management (UK), a visiting Post Doctorate research fellow at Oulu Business School (Finland) and a senior research associate at the Estonian Business School (Estonia). Currently, he is a business consultant at BESM (UK). Mohamed Mousa worked previously as a full-time teaching assistant at Menoufia University (Egypt). He also was the business development executive and later a manager at Sahara Company (Egypt, UK and Turkey) for Paints and Fertilizers. He has successfully obtained MSc in executive leadership, University of Ulster, UK and PhD in management science, Estonian Business School, Estonia. Mohamed has 15 publications in management and organisation science.

Correspondence to: Mohamed Mousa, PhD, Estonian Business School, Lauteri 3, 10114 Tallinn, Estonia, e-mail: Mohamed.mousa@ebs.ee

\section{Acknowledgements and Financial Disclosure}

The author would like to thank Michael Haagensen for his useful comments, which allowed to increase the value of this article.

\section{Copyright and License}

This article is published under the terms of the Creative Commons

Attribution - NoDerivs (CC BY-ND 4.0) License

http://creativecommons.org/licenses/by-nd/4.0/

Published by the Centre for Strategic and International Entrepreneurship - Krakow, Poland 